\title{
Avaliação de probióticos (Pediococcus acidilactici e Bacillus subtilis) após o desmame e efeitos no desempenho dos leitões
}

\section{The probiotics (Pediococcus acidilactici and Bacillus subtilis) evaluation after weaning and effects on the piglets performance}

\author{
Caio Abércio da Silva ${ }^{1 *}$; Edgard Hideaki Hoshi²; \\ Graziela Drociunas Pacheco²; Marcus Vinícius Briganó ${ }^{2}$
}

Resumo

\begin{abstract}
O experimento foi conduzido visando avaliar o uso das bactérias probióticas Pediococcus acidilactici associada ou não ao Bacillus subtilis em rações para leitões recém-desmamados (21 dias) e seus efeitos no desempenho até os 63 dias de idade. Foram utilizados 210 animais submetidos aos seguintes tratamentos: T1- ração com Pediococcus acidilactici; T2 - ração com Pediococcus acidilactici + Bacillus subtilis; e T3 - ração isenta de probiótico. Foram avaliados o ganho diário de peso, o consumo diário de ração, a conversão alimentar, a ocorrência de diarréias e a taxa de mortalidade. O delineamento experimental foi em blocos casualizados, com 3 tratamentos e 7 repetições, sendo as médias comparadas pelo teste de Duncan. Observou-se ao final do experimento que animais que receberam o Pediococcus acidilactici associada ou não ao Bacillus subtilis (T1 e T2) apresentaram melhor conversão alimentar $(\mathrm{P}<0,05)$ com relação ao grupo controle. A utilização destas bactérias não determinou ocorrência de diarréias. Os probióticos utilizados podem ser empregados com resultados positivos na conversão alimentar de leitões na fase de creche.

Palavras-chave: Microbiota, desempenho, diarréia, suínos
\end{abstract}

\begin{abstract}
The experiment was conducted with the goal to evaluate the use of rations with Pediococcus acidilactici and Pediococcus acidilactici plus Bacillus subtilis as probiotics to weaned piglets (21 days) and the effects on the performance until 63 day of age. 210 piglets were submitted to the folowing treatments: T1ration with Pediococcus acidilactici; T2- ration with Pediococcus acidilactici + Bacillus subtilis; and T3- ration without probiotic. Were evaluated the daily weight gain, daily feed intake and the conversion rate, the dirrohea ocurrence and the mortality rate. The experimental design was a randomized blocks, with 3 treatments and 7 replications, been the means compared by Duncan's Test. At the end of the experiment the animals that received the ration with Pediococcus acidilactici and the ration with Pediococcus acidilactici plus Bacillus subtilis (T1 and T2) presented a better conversion rate $(\mathrm{P}<0.05)$ than the control group. The use of these bacterias did not result a diarrohea ocurrence. The probiotics used can be indicated with positive results on conversion rate to piglets in the nursery phase.
\end{abstract}

Key words: Microbiota, performance, diarrohea, swine

\footnotetext{
1 Professor Doutor. Departamento de Zootecnia, Centro de Ciências Agrárias, Universidade Estadual de Londrina, Londrina - PR. E-mail: casilva@uel.br.

2 Alunos de Pós Graduação em Ciência Animal da Universidade Estadual de Londrina.

* Autor para correspondência.
} 


\section{Introdução}

Probióticos são suplementos alimentares que contêm bactérias vivas que produzem efeitos benéficos no hospedeiro, favorecendo o equilíbrio de sua microbiota intestinal. No entanto, Havenaar e Huis In't Veld (1992) consideraram que são culturas únicas ou mistas de microrganismos que, administrados a animais ou humanos, produzem efeitos benéficos no hospedeiro por incremento das propriedades da microbiota nativa.

Os probióticos são usados em medicina humana na prevenção e tratamento de doenças, na regulação da microbiota intestinal, em distúrbios do metabolismo gastrintestinal, como imunomoduladores, e na inibição da carcinogênese. Em medicina veterinária, além dessas aplicações, podem ser usados como promotores de crescimento, constituindo-se em uma alternativa aos antibióticos, cujo uso indiscriminado pode selecionar cepas resistentes.

O modo de ação dos probióticos ainda não foi completamente esclarecido, embora tenham sido sugeridos vários processos que podem atuar independentemente ou associados. Um deles é a exclusão competitiva, em que o probiótico competiria com os patógenos por sítios de fixação e nutrientes, impedindo sua ação transitoriamente (CROSS, 2002). A exclusão competitiva explicaria a necessidade da administração continuada e de elevadas doses dos probióticos para manifestar seus efeitos. Os probióticos podem também afetar patógenos através da síntese de bacteriocinas (NAIDU; BIDLACK; CLEMENS, 1999), de ácidos orgânicos voláteis (JIN; MARQUARDT; BAIDOO, 2000; OGAWA et al., 2001) e de peróxido de hidrogênio (NAIDU; BIDLACK; CLEMENS, 1999), ou atuar sobre o metabolismo celular, reduzindo a concentração de amônia no organismo (KOZASA, 1986) e liberando enzimas como a lactase (DE VRESE et al., 2001).

A maioria dos estudos demonstram que bactérias ácido-lácticas, utilizadas como probióticos, têm efeito imunoestimulante em animais e no homem, apesar de ainda não estarem esclarecidos os mecanismos pelos quais isto ocorre (CROSS, 2002). Esse efeito pode estar relacionado à capacidade dos microrganismos e do probiótico interagirem com as placas de Peyer e as células epiteliais intestinais, estimulando as células B produtoras de $\operatorname{IgA}$ e a migração de células $\mathrm{T}$ do intestino (PERDIGÓN; HOLGADO, 2000). Também tem sido demonstrado que os probióticos favorecem a atividade fagocítica inespecífica dos macrófagos alveolares, sugerindo uma ação sistêmica por secreção de mediadores que estimulariam o sistema imune (CROSS, 2002).

Particularmente, na suinocultura, a fase pósdesmame apresenta-se como um momento muito crítico para o leitão, na qual o uso de um probiótico, pelas suas características, pode reduzir os transtornos digestivos, estimular o estado imunitário e melhorar o desenvolvimento dos leitões na fase. Segundo Maenz, Patience e Wolynetz (1993), leitões desmamados entre três e quatro semanas de idade passam por uma fase delicada, onde o consumo de alimento é baixo e o ganho de peso corporal é pequeno ou ausente.

Diante destas considerações, esforços constantes têm sido dispensados visando promover um maior desempenho no período pós-desmame. Paralelamente, pelo momento que representa o desmame, a utilização de antibióticos e quimioterápicos, comumente feita como medida preventiva aos problemas diarréicos freqüentemente observados no período e pelo suporte à imunodeficiência dos leitões na fase, tem sofrido pressões pelas correntes que defendem o banimento de promotores de crescimento das rações e pela visão do consumidor moderno.

Neste sentido, este trabalho avaliou o uso do Pediococcus acidilactici associada ou não ao Bacillus subtilis nas rações sobre o desempenho e o estado sanitário dos leitões recém-desmamados até o final do período de creche. 


\section{Material e Métodos}

O experimento foi conduzido no período compreendido entre o dia 02 de agosto e o dia 15 de setembro de 2004, em uma granja comercial de suínos de ciclo completo, localizada no norte do estado do Paraná, com 170 matrizes híbridas comerciais, sendo ciclo completo, utilizando o sistema all in all out nas fases de maternidade e creche e manejo contínuo nas demais fases.

O experimento foi iniciado por ocasião do desmame, realizado em média aos 21 dias de idade, sendo concluído aos 63 dias de idade.

Os animais foram alojados em baias coletivas com piso totalmente ripado (sistema de creche suspensa) com capacidade para 10 a 12 animais por baia. Foram preservadas, durante o alojamento, a densidade média de $0,25 \mathrm{~m}^{2} /$ animal.

Ao total foram avaliados 210 animais, com peso médio inicial de $5,76 \mathrm{~kg}$ e idade média de 21 dias. Os animais receberam rações produzidas na propriedade, formuladas com núcleos comerciais, atendendo as exigências nutricionais específicas para a fase (Tabela 1).

Os tratamentos foram orientados na fase de creche, correspondendo a: T1 - ração com Pediococcus acidilactici ( 1 x $10^{9} \mathrm{UFC} / \mathrm{Kg}$ de ração), T2 - ração com Pediococcus acidilactici (8 x $10^{9} \mathrm{UFC} / \mathrm{Kg}$ de ração) + Bacillus subtilis $(2 \times$ $10^{9} \mathrm{UFC} / \mathrm{Kg}$ de ração) e T3- ração isenta de probiótico. Cada tratamento foi implementado no início da desmama, sendo mantido por 42 dias. Os probióticos foram adicionados às rações dos tratamentos 1 e 2 na concentração de $0,01 \%$

Foram avaliados o ganho diário de peso, o peso final, o consumo diário de ração e a conversão alimentar.

Também foi verificado a presença de diarréia no período, sendo realizados duas observações por dia (1 hora de manhã e 1 hora à tarde) de acordo com a metodologia proposta por Madec, Josse e Chantal (1982) e Vieira, Vieira e Madec (1989).

No final do período computou-se a taxa de mortalidade observada nos tratamentos.

Para verificar a viabilidade econômica da utilização do probiótico nas rações pré-iniciais e iniciais foi determinado o custo médio em ração por quilograma de peso vivo (Yi) durante o período experimental, conforme Bellaver (1985):

$$
Y i=\mathrm{Q} i \times \mathrm{P} i \text {, onde: }
$$

\section{$\mathrm{G} i$}

$Y i=$ custo médio em ração por quilograma ganho no $i$-ésimo tratamento;

$\mathrm{P} i=$ preço médio por quilograma da ração utilizada no $i$-ésimo tratamento;

Q $i=$ quantidade média de ração consumida no $i$ ésimo tratamento;

$\mathrm{G} i=$ ganho médio de peso do $i$-ésimo tratamento.

Na seqüência, calculou-se o Índice de Eficiência Econômica (IEE) e o Índice de Custo Médio (IC), propostos por Barbosa et al. (1992).

$$
\begin{gathered}
\mathrm{IEE}=\operatorname{MCe} \times 100 \text { e IC }=\text { CTe } i \text { x 100, onde: } \\
\text { CTe } i \quad \text { MCe }
\end{gathered}
$$

$\mathrm{MCe}=$ menor custo médio observado em ração por quilograma de peso vivo ganho entre os tratamentos; $\mathrm{CTe} i=$ custo médio do tratamento $i$ considerado.

Os valores (preços/quilograma) dos ingredientes utilizados na elaboração dos custos foram obtidos na região de Londrina no mês de setembro de 2004, sendo: milho ( $\mathrm{R} \$ 0,24)$, farelo de soja $(\mathrm{R} \$ 0,60)$, max adv. (R\$ 8,60), avant $65 \%(\mathrm{R} \$ 4,20)$, fosfato bicálcico ( R\$ 0,80), calcário $(\mathrm{R} \$ 0,10)$, banha $(\mathrm{R} \$ 2,00)$, sal comum ( $\mathrm{R} \$ 0,20)$, concentrado pré-inicial $(\mathrm{R} \$ 3,80)$, premix inicial $(\mathrm{R} \$ 5,51)$, premix mineral $(\mathrm{R} \$ 2,90) \mathrm{e}$ agrocobre $(\mathrm{R} \$ 5,44)$. 
Silva, C. A. et al.

Tabela 1. Composição centesimal das rações pré-inicial I, pré-inicial II, inicial I e inicial II utilizadas durante o período experimental.

\begin{tabular}{|c|c|c|c|c|}
\hline Ingredientes (\%) & Pré-inicial I & Pré-inicial II & Inicial I & Inicial II \\
\hline Milho & 21,0 & 35,0 & 50,2 & 65,7 \\
\hline Farelo de soja & 12,0 & 22,5 & 27,6 & 29,6 \\
\hline Aditivo $^{1}$ & 0,5 & 0,5 & 0,5 & 0,5 \\
\hline Aditivo $^{2}$ & 65,0 & - & - & - \\
\hline Banha & 1,5 & 2,0 & 2,4 & 1,0 \\
\hline Concentrado Pré-inicial $^{3}$ & - & 40,0 & 18,0 & - \\
\hline Fosfato bicálcico & - & - & 0,6 & 1,7 \\
\hline Calcário & - & - & 0,05 & 0,45 \\
\hline $\mathrm{Sal}$ & - & - & 0,35 & 0,5 \\
\hline Premix inicial $^{4}$ & - & - & 0,15 & 0,3 \\
\hline Premix mineral $^{5}$ & - & - & 0,05 & 0,1 \\
\hline Aditivo $^{6}$ & - & - & 0,1 & 0,15 \\
\hline \multicolumn{5}{|l|}{ Valores Calculados ${ }^{7}$} \\
\hline Proteína Bruta (\%) & 19,708 & 23,623 & 21,523 & 19,023 \\
\hline Energia Metabolizável (Kcal/Kg) & $3.499,48$ & $3.130,37$ & $3.166,95$ & $3.223,367$ \\
\hline Fibra bruta $(\%)$ & 1,778 & 2,669 & 2,824 & 2,98 \\
\hline Cálcio (\%) & 0,724 & 0,831 & 0,878 & 0,925 \\
\hline Fósforo total (\%) & 0,686 & 0,796 & 0,725 & 0,656 \\
\hline Fósforo disponível (\%) & 0,536 & 0,567 & 0,497 & 0,428 \\
\hline Lisina (\%) & 1,657 & 1,408 & 1,313 & 1,114 \\
\hline Extrato etéreo (\%) & 7,387 & 4,953 & 4,893 & 4,876 \\
\hline Lactose (\%) & 19,5 & 8,0 & 4,0 & - \\
\hline
\end{tabular}

${ }^{1} \mathrm{Max}$ Adv. (valores calculados por kg de produto): fósforo, 0,05g; extrato etéreo, 1\%; matéria fibrosa, 1\%; matéria mineral, $8 \%$; proteína bruta, 35\%; umidade, 13\%; cálcio, 0,05g; metionina, $110.000 \mathrm{mg}$; lisina, $170.000 \mathrm{mg}$.

${ }^{2}$ Avant 65\%(valores calculados por $\mathrm{kg}$ de produto): ácido fólico, 2,03mg, ácido pantotênico 63,64mg, antioxidante, 299,95mg; promotor de crescimento, 155mg; colina, 2,55g; cloro, 6g; cobre, 325,5mg; ferro, 395,65mg; iodo, 1,6mg; lisina, 16,5g; magnésio, 1,12g; manganês, 113,64mg; metionina, 7,3g; potássio, 4g; selênio, 1,02mg; sódio, 4,5g; vit. A, 22.950 UI; vit. B12, 85mcg; vit.D3, $5.100 \mathrm{UI}$; vit. E, 255mg; vit. K3, 10,2mg; zinco, 3.853,5mg; enxofre, $1,15 \mathrm{~g}$; niacina, 88 mg; biotina, 0,42mg; piridoxina, 12,61 mg; tiamina, 9,81mg; riboflavina, 24,36mg; Ca, $11 \mathrm{~g}$; extrato etéreo, 4\%; P, 7,8g; matéria fibrosa, 3\%; matéria mineral, $13 \%$; proteína bruta, $15 \%$; umidade, $13 \%$.

${ }^{3}$ Concentrado Pré-Inicial (valores calculados por kg de produto): ácido pantotênico, 91,5mg; antioxidante, 615mg; promotor de crescimento, 172mg; colina, 3,4g; cobre, 698,1mg; cobalto, 0,63; ferro, 606,5mg; iodo, 5,04mg; lisina, 17,6 g; manganês, 170,6mg; metionina, 7,3g; potássio, 4g; selênio, 1,8mg; sódio, 10,8g; vit. A, 32.000 UI; vit. B12, 135,9mcg; vit. D3, 12.000 UI, vit. E, 330mg; vit. K3, 32mg; zinco, 438mg; enxofre, 1,86g; niacina, 170mg, biotina, 0,8mg; piridoxina, $12 \mathrm{mg}$; tiamina, 10,7mg; riboflavina, 32,4mg; Ca, 25g; extrato etéreo, 2\%; P, 14g; matéria fibrosa, 3\%; matéria mineral, $13 \%$; proteína bruta, $20 \%$; umidade, $13 \%$.

${ }^{4}$ Premix inicial (valores calculados por kg de produto): ácido fólico, 420mg; ácido pantotênico, 7,350mg; antioxidante, $1.500 \mathrm{mg}$; biotina, 16,56mg; colina, 126g; niacina, 13.650mg; piridoxina, 700mg; riboflavina, 2.100; selênio, 136,5mg; tiamina, 700mg; vit. A, $2.800 \mathrm{UI}$; vit. B12, 11.550mcg; vit. D3, 1.050 UI, vit. E, 10.500mg; vit. K3, 2.800mg.

${ }^{5}$ Premix mineral (valores calculados por kg de produto): zinco, 77.999; cobre, 15.750mg; manganês, 41.850; cálcio, 98.800mg; cobalto, $135 \mathrm{mg}$; iodo, $1.470 \mathrm{mg}$; ferro, $26.250 \mathrm{mg}$.

${ }^{6}$ Agrocobre (valores calculados por kg de produto): zinco, 30.000mg; ferro, 30.000mg; cobre, $115.000 \mathrm{mg}$. 
O delineamento experimental foi em blocos casualizados, com 3 tratamentos e 7 repetições por tratamento. Aos dados de desempenho foi aplicada a análise de variância, sendo as médias comparadas pelo teste de Duncan. Para os dados relativos à avaliação da ocorrência de diarréia e mortalidade foi utilizado o teste de qui-quadrado. Os dados foram submetidos ao programa de análise estatísticas SAEG (UNIVERSIDADE FEDERAL DE VIÇOSA, 1997).

\section{Resultados e Discussão}

Os resultados do desempenho estão apresentados nas Tabelas 2.
Os resultados demonstraram que não houve diferença estatística $(P>0,05)$ entre os tratamentos para o peso inicial, peso final, ganho diário de peso e consumo diário de ração. Entretanto, verificou-se uma melhora na conversão $(\mathrm{P}<0,05)$ dos animais que receberam probiótico (Pediococcus acidilactici associada ou não ao Bacillus subtilis). Este fato pode ser explicado pelo princípio dos probióticos em melhorar a digestibilidade dos nutrientes e estabelecer uma competição entre os microrganismos benéficos a microrganismos indesejáveis, favorecendo os índices de conversão alimentar.

Tabela 2. Resultados do peso inicial (PI), peso final (PF), ganho diário de peso (GDP), consumo diário de ração (CDR) e conversão alimentar (CA).

\begin{tabular}{cccccc}
\hline Tratamentos & \multicolumn{5}{c}{ Parâmetros } \\
\cline { 2 - 6 } & PI (Kg) & PF (Kg) & GDP (Kg) & CDR (Kg) & CA \\
\hline Pediococcus acidilactici & $5,75 \mathrm{a}$ & $26,94 \mathrm{a}$ & $0,504 \mathrm{a}$ & $0,700 \mathrm{a}$ & $1,385 \mathrm{~b}$ \\
Pediococcus acidilactici + Bacillus subtilis & $5,75 \mathrm{a}$ & $26,62 \mathrm{a}$ & $0,497 \mathrm{a}$ & $0,676 \mathrm{a}$ & $1,362 \mathrm{~b}$ \\
ração isenta de probiótico & $5,79 \mathrm{a}$ & $26,35 \mathrm{a}$ & $0,490 \mathrm{a}$ & $0,746 \mathrm{a}$ & $1,523^{\mathrm{a}}$ \\
\hline
\end{tabular}

* médias seguidas de letras diferentes, nas colunas, diferem entre si pelo teste de Duncan $(\mathrm{P}<0,05)$

Embora os resultados não tenham indicado diferença entre os tratamentos que utilizaram probióticos (T2 e T3), a literatura cita vantagens na utilização do gênero Bacillus sobre as bactérias ácido lácticas (Pediococcus acidilactici) como probióticos. Esta vantagem reside basicamente em sua capacidade de esporular, o que lhes confere maior sobrevivência durante o trânsito estomacal (HOA et al., 2000), e durante a elaboração, transporte e armazenamento das rações (GIL TURNES et al., 1999). Não obstante, ambos probióticos promovam o ganho de peso e o controle de diarréias, e reduzam a mortalidade perinatal em suínos (ZANI et al., 1998), atribui-se com mais especificidade às bactérias do gênero Bacillus sua capacidade de estimular a resposta imune e serem utilizadas como imunomoduladores (MÁRA et al., 1994).
Quanto a diarréia foram verificadas duas ocorrências para o grupo controle (ração isenta de probiótico), não representando todavia efeitos de diferença $(\mathrm{P}>0,05)$ entre os tratamentos.

Quanto a mortalidade, os resultados não apontaram diferenças $(\mathrm{P}>0,05)$ entre os tratamentos. Foi verificada um caso de morte no grupo tratado com ração com Pediococcus acidilactici associada Bacillus subtilis, duas no tratamento que empregou Pediococcus acidilactici e duas no grupo controle (isenta de probiótico). As mortes foram de caráter súbito, não indicando existir relação com os tratamentos.

Estes resultados (baixa presença de diarréia e baixo índice de mortalidade) indicam, de forma genérica, que a qualidade do manejo sanitário da 
granja, especialmente da creche, era elevada, como também a ocorrência de uma possível ação imunoestimuladora dos probióticos utilizados (PERDIGÓN; HOLGADO, 2000; CROSS, 2002).
Na Tabela 3 estão apresentados os custos médios em ração por quilograma de peso vivo ganho, os índices de custo e os índices de eficiência econômica para os quatro tratamentos utilizados.

Tabela 3. Custo médio em ração por quilograma de peso vivo ganho, índice médio de custo e índice de eficiência econômica de leitões (56-150 dias), de acordo com os níveis de inclusão do grão de girassol.

\begin{tabular}{cccc}
\hline \multirow{2}{*}{ Parâmetros } & \multicolumn{3}{c}{ Tratamentos } \\
\cline { 2 - 4 } & $\begin{array}{c}\text { Pediococcus } \\
\text { acidilactici }\end{array}$ & $\begin{array}{c}\text { Pediococcus acidilactici }+ \\
\text { Bacillus subtilis }\end{array}$ & $\begin{array}{c}\text { ração isenta de } \\
\text { probiótico }\end{array}$ \\
\hline Custo em ração $(\mathrm{R} \$ \mathrm{~kg})$ & 1,31 & 1,35 & 1,53 \\
Índice de custo & 100,00 & 102,53 & 116,42 \\
Índice de eficiência econômica & 100,00 & 97,53 & 85,89 \\
\hline
\end{tabular}

É possível indicar que a melhor dieta em termos de índice de eficiência econômica e de custo foi o tratamento com a inclusão do Pediococcus acidilactici, seguida pelo tratamento em que foi associado o Pediococcus acidilactici ao Bacillus subtilis e por fim o grupo controle. Entretanto, pode ser verificado que a associação do Pediococcus acidilactici com o Bacillus subtilis não demonstrou grandes benefícios econômicos.

A eficiência técnica dos tratamentos utilizados em relação ao grupo controle permite concluir que seus efeitos foram positivos, entretanto, os probióticos avaliados, como qualquer outra composição probiótica, merecem uma avaliação prévia das variáveis presentes na granja, com destaque aos desafios sanitários, à composição da ração, ao manejo alimentar, entre outros. Possivelmente, por este grande número de fatores, os resultados dos estudos com probióticos muitas vezes são conflitantes (MAXWELL; STWART, 1995).

\section{Conclusões}

A utilização do probiótico Pediococcus acidilactici e da associação probiótica Pediococcus acidilactici mais Bacillus subtilis melhorou a conversão alimentar com repercussões positivas na eficiência econômica dos tratamentos.

\section{Referências}

BARBOSA, H. P.; FIALHO, E. T.; FERREIRA, A. S.; LIMA, G. J. M.; GOMES, M. F. M Triguilho para suínos nas fases inicial de crescimento, crescimento e terminação. Revista da Sociedade Brasileira de Zootecnia, Viçosa, v.21, n.5, p.827-837, 1992.

BELLAVER, C.; FIALHO, E. T.; PROTAS, J. F. S.; GOMES, P. C. Radícula de malte na alimentação de suínos em crescimento e terminação. Pesquisa Agropecuária Brasileira, Brasília, v.20, n.8, p.969-974, 1985.

CROSS, M. L. Microbes versus microbes: immune signals generated by probiotic lactobacilli and their role in protection against microbial pathogens. FEMS Immunology and Medical Microbiology, Amsterdam, v.34, n.4, p.245-253, 2002.

DE VRESE, M.; STEGELMANN, A.; RICHTER, B.; FENSELAU, S.; LAUE, C.; SCHREZENMEIR, J. Probioticscompensation for lactase insufficiency. American Journal of ClinicalNutrition, New York, v.73, n.2, p.421S-429S, 2001.

GIL-TURNES, C.; SANTOS, A. F.; CRUZ, F. W.; MONTEIRO, A. V. Properties of the Bacillus cereus strain used in probiotic CenBiot. Brazilian Journal of Microbiology, Sao Paulo, v.30, n.1, p.11-14, 1999.

HAVENAAR, R.; HUIS IN'T VELD, M. J.H. Probiotics: a general view. In: WOOD, B.J.B. Lactic acid bacteria in health and disease 1. Amsterdam: Elsevier Applied Science, 1992. p.151-170.

HOA, N.T.; BACCIGALUPI, L.; HUXHAM, A.; SMERTENKO, A.; VAN, P. H.; AMMENDOLA, S.; RICCA, E.; CUTTING, S. M. Characterization of Bacillus species used for oral bacteriotherapy and bacterioprophylaxis of gastrointestinal disorders. Applied and Environmental Microbiology, Washington, v.66, n.12, p.5241-5247, 2000. 
JIN, L. Z.; MARQUARDT, R. R.; BAIDOO, S. K. Inhibition of enterotoxigenic Escherichia coli K88, K99 and 987P by the Lactobacillus isolates from porcine intestine. Journal of the Science of Food and Agriculture, London, v.80, n.5, p.619-624, 2000.

KOZASA, M. Toyocerin (Bacillus toyoi) as growth promotor for animal feeding. Microbiology Aliments Nutrition, n.4, p.121-135, 1986.

MADEC, F.; JOSSE, J.; CHANTAL, A. Evaluation d'une methode multifactorielle dans L' analyse dês troubles digestifs du sevrage. Journees Recherche Porcine en France, Saint-Gilles, v.14, p.379-386, 1982.

MAENZ, D. D.; PATIENCE, J. F.; WOLYNETZ, M. S. Effect of water on the performance of newly weaned pigs offered medicated and unmedicated feed. Canadian Journal of Animal Science, Ottawa, v.73, n.3, p.669-672, 1993.

MÁRA, M.; OCENASKOVA, J.; NOVAKOVA, M.; JULAK, J.; MENCIKOVA, E. Resistance to infection and activation of monocyte-macrophage system caused by Bacillus firmus and its fractions. Folia Microbiológica, Praha, v.39, n.2, p.147-151, 1994.

MAXWELL, F. J.; STEWART, C. S. The microbiology of the gut and the role of probiotics. In: . The

neonatal pig: development and survival. Wallingford, Oxon.: CAB International, 1995. p.155-186

NAIDU, A. S.; BIDLACK, W. R.; CLEMENS, R. A. Probiotic spectra of lactic acid bacteria (LAB). Critical Reviews in Food Science and Nutrition, Boca Raton, v.38, n.1, p.13-126, 1999.
OGAWA, M.; SHIMIZU, K.; NOMOTO, K.; TANAKA, R.; HAMABUTA, T.; YAMASAKI, S.; TAKEDA, T.; TAKEDA, Y. Inhibition of in vitro growth of Shiga toxinproducing Escherichia coli O157:H7 by probiotic Lactobacillus strains due to production of lactic acid. International Journal of Food Microbiology, Amsterdam, v.68, n.1-2, p.135-140, 2001.

PERDIGÓN, G.; HOLGADO, A. P. R. Mechanisms involved in the immunostimulation by lactic acid bacteria. In: - Probiotics 3: immunodulation by the gut microflora and probiotics. Dordrecht : Kluwer Academic, 2000.

UNIVERSIDADE FEDERAL DE VIÇOSA - UFV. SAEGSistema de análises estatísticas e genéticas. Viçosa: Ed. UFV, 1997. (Manual do usuário, versão 7.1)

VIEIRA, R. P.; VIEIRA, H. P.; MADEC, F. Aplicação da analise multidimensional na prevenção da patologia digestiva do desmame em suinocultura intensiva. Revista Portuguesa de Ciências Veterinárias, Lisboa, v.84, n.492, p.229-241, 1989.

ZANI, J. L.; CRUZ, F. W.; SANTOS, A. F.; GIL-TURNES, C. Effect of probiotic CenBiot on the control of diarrhoea and feed efficiency in pigs. Journal of Applied Microbiology, Oxford, v.84, n.1, p.68-71, 1998. 